\title{
Control van financiële derivaten, een empirisch onderzoek in Nederland
}

Mw. Drs. E.M.A. van Schoten

\section{Inleiding}

Het gebruik van financiële derivaten is niet meer weg te denken uit het bedrijfsleven. De voorbeelden van situaties waar het (onverantwoord) gebruik van derivaten tot grote verliezen en schandalen heeft geleid, zijn echter talrijk. Zo kunnen onder andere worden genoemd: Barings, Procter \& Gamble, Metallgesellschaft en een aantal Nederlandse woningcorporaties. Als gevolg van deze schandalen is de laatste jaren een stroom van publicaties op gang gekomen met als thema het beheersen van het gebruik van derivaten. Vanuit het bankwezen (bijvoorbeeld: Basle Comittee on Banking Supervision, 1994) worden hieromtrent aanbevelingen gedaan. Ook zijn er vele bedrijfseconomische analyses (bijvoorbeeld: Boot en Ligterink, 1995) verschenen waarin wordt onderzocht op welke punten de beheersingsmaatregelen en/of het gebruik van derivaten tekortschoten. Vanuit de not-for-profit sector zijn eveneens verscheidene richtlijnen gegeven voor hel implementeren van beheersingsmaatregelen voor het gebruik van derivaten. Het Ministerie van Financiën (1995) heeft bijvoorbeeld een circulaire uitgevaardigd over het gebruik van derivaten door openbare lichamen die onder de Wet financiering

Mw. Drs. E.M.A van Schoten RA is werkzaam als projectleider vaktechniek bij de Directie Accountancy Rijksoverheid van het Ministerie van Financiën en is daarnaast bezig met een promotieonderzoek naar de control en audit van financiële derivaten aan de Vrije Universiteit. Zij dankt Prof. L.C. van Zutphen RA, Prof. Dr. H.G. Eijgenhuijs en Drs. P.J.W. Duffhues voor hun commentaar op een eerdere versie van dit artikel. Het artikel is op persoonlijke titel geschreven. lagere overheid vallen. De Nationale Woningraad (1994), een koepelorganisatie voor woningcorporaties, heeft een handreiking gemaakt voor het opstellen van een financieel statuut. Dit is een interne instructie waarin ten aanzien van het financiële beleid, waaronder het gebruik van derivaten, onder meer de verantwoordelijkheden en bevoegdheden worden vastgelegd.

Het risicomanagement neemt in veel van deze publicaties een belangrijke plaats in. In dit artikel staat de vraag centraal in hoeverre de beheersings. maatregelen die in deze publicaties worden aanbevolen, in de praktijk worden nageleefd.

\section{Derivaten en risicomanagement}

Uit de kernactiviteiten van een organisatie vloeien financiële risico's voort. Met behulp van derivaten kunnen deze risico's worden afgedekt (gehedged). In het algemeen worden de volgende basisvormen van derivaten onderscheiden: opties, ruilcontracten (swaps), futures en forwards.

Vervolgens kan een onderscheid worden gemaakt tussen interne en externe hedging. Interne hedging is het doorschuiven van de extra (rente)kosten op de afnemers en/of toeleveranciers. Externe hedging is het afwentelen van de risico's op andere marktpartijen. Het gaat in dit artikel primair om externe hedging.

Het Bazels Comité (1994) definieert een derivaat als 'a financial contract whose value depends on the values of one or more underlying assets or indexes'.' Derivaten kunnen voor verschillende doeleinden worden gebruikt, namelijk voor het afdekken van rente- en valutarisico's, voor het optimaliseren van financierings- en 
beleggingsbeslissingen en als zelfstandig middel tot winst. Het onderscheid tussen deze doelstellingen is van belang. Bij het afdekken van rente- en valutarisico's is er een duidelijke relatie te leggen tussen het derivaat en de exposure. Bij het optimaliseren van financierings- en beleggingsbeslissingen, bijvoorbeeld voorfinanciering, is deze relatie in het algemeen minder duidelijk. Er is dan wel sprake van een exposure, maar niet alleen van het afdekken van een risico. Men probeert dan de mogelijkheid open te houden om van toekomstige gunstige marktontwikkelingen te profiteren. Bij het gebruik van derivaten als zelfstandig middel tot winst is er geen relatie met een exposure. Naarmate de relatie tussen exposures en derivaten minder duidelijk is te leggen, zal de beheersing van het gebruik van derivaten zich meer moeten toespitsen op het beheersen van risicosoorten, dan op het beheersen van individuele transacties.

Böni (1994) vergelijkt de risico's van derivaten met concentrische cirkels (zie figuur 1). De binnenste cirkel staat voor het kredietrisico, dit is het risico dat de kredietnemer niet aan zijn verplichtingen kan voldoen. Dit risico valt uiteen in debiteurenrisio, landenrisico en het risico dat de creditrating van de tegenpartij daalt. De tweede cirkel staat voor het marktrisico. Marktrisico is het risico dat de waarde van een contract wijzigt ten gevolge van veranderingen in de prijs van het onderliggende product en andere prijsbepalende factoren. Aangezien derivaten een sterke hefboomwerking hebben, is het noodzakelijk om het marktrisico te monitoren. Voor zeer actieve participanten is het dagelijks volgen van de marktwaarde een vereiste.

Figuur I: Risico's samenhangend met het gebruik van derivaten

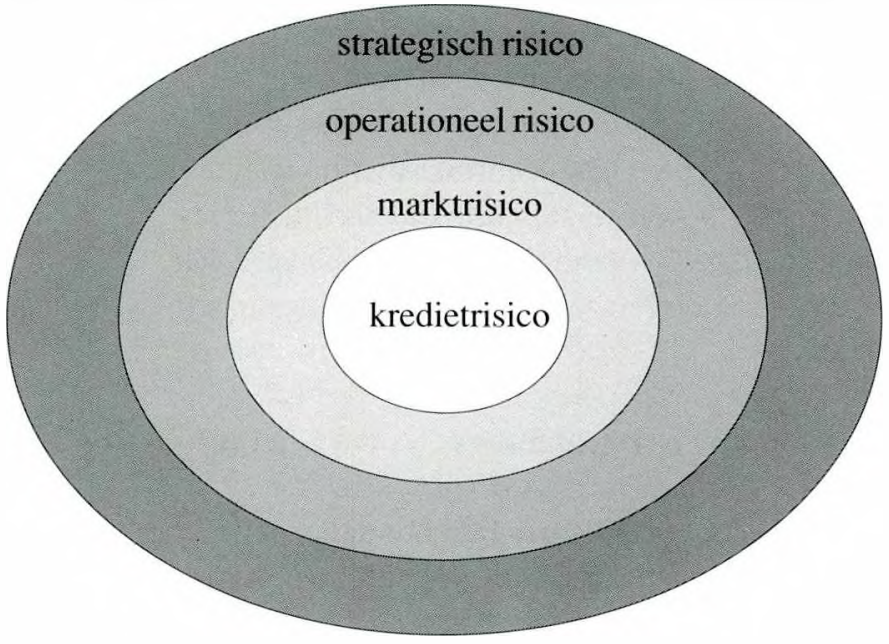

De derde cirkel geeft het operationele risico weer. Uit de voorgaande cirkels is al duidelijk geworden dat er vele risico's zijn die moeten worden beheerst. Hiervoor zijn maatregelen in de interne organisatie nodig, alsmede analysemethoden en adequate informatievoorziening. De kans op bewuste en onbewuste fouten in het aangaan en vastleggen van derivatentransacties waarvan de oorzaak ligt in de interne organisatie, wordt met de term operationeel risico aangeduid.

De risico's uit de drie cirkels gelden voor elke organisatie. De vierde cirkel verwijst naar het strategische risico. Dit is een soort ondernemingsrisico, dat vooral van belang is voor financiële instellingen. Deze organisaties kunnen grote posities in derivaten aangaan. Het gevaar bestaat dat zij bijvoorbeeld de wensen van hun cliënten verkeerd inschatten of dat de kosten van de transacties uit de hand lopen, waardoor hun concurrentiepositie en lange- en middellangetermijnontwikkeling negatief kan worden beïnvloed.

Het beheersen van deze risico's vereist een vorm van risicomanagement. Het Bazels Comité (1994) stelt dat het risicomanagement drie basiselementen omvat:

1 voldoende inzicht in derivaten en daarmee samenhangende risico's bij de raad van bestuur en het hogere management;

2 een adequaat risicomanagementproces dat limieten, risicomaatstaven, informatiesystemen, monitoringsystemen en managementinformatie omvat;

3 internal control en audit procedures.

Managers hebben echter een verschillende visie op risico en risicoreductie. Het beleid gericht op het gebruik van financiële derivaten zal daarom duidelijke uitspraken moeten doen over:

- de doelstellingen van het gebruik van derivaten;

- de voorwaarden voor het gebruik van derivaten;

- de beheersingsactiviteiten voor het gebruik van derivaten, informatie en communicatie en monitoring.

Deze uitspraken moeten zijn gebaseerd op een analyse van de karakteristieken van derivaten en strategieën voor het gebruik van derivaten, resulterend in voor de organisatie geschikte en ongeschikte producten en strategieën.

Bij het indelen van derivaten kunnen de 
volgende karakteristieken worden onderkend:

I Hefboomwerking. Er zijn derivaten waarbij een kleine verandering in de onderliggende waarde kan leiden tot een grote winst of een groot verlies. Het beleid van een organisatie zal richtlijnen moeten geven voor de gewenste mate van hefboomwerking en de wijze waarop de hefboomwerking wordt gemeten.

2 Liquiditeit. De organisatie zal richtlijnen moeten ontwikkelen voor de gewenste mate van liquiditeit van derivaten. Dit kan ertoe leiden dat bepaalde over-the-counter (OTC) derivaten van gebruik worden uitgesloten. OTC-derivaten worden niet ter beurze verhandeld.

3 Standaardisatie. De organisatie zal richtlijnen moeten hebben voor het gebruik van (niet gestandaardiseerde) OTC-derivaten en het analyseren van daarmee samenhangende contracten.

In het risicobeleid moet een aantal aspecten worden meegenomen, zoals de mate van risicoaversie van de organisatie, de visie op de componenten van het 'business risk' en de kennis van en ervaring met derivaten in de organisatie. Periodiek zal een analyse moeten plaatsvinden van de effectiviteit van de derivatentransacties in relatie tot de doelstellingen van de organisatie. Al deze maatregelen behoren tot de interne beheersing van een organisatie.

\section{Beheersingsmaatregelen}

In 1992 verscheen in de Verenigde Staten van Amerika het rapport van het Committee of Sponsoring Organizations of the Treadway Commission (COSO, 1994). Kort daarna verschenen in Canada twee rapporten van het Canadian Institute of Chartered Accountants (1994 en 1995) die handelen over dezelfde materie. In het verleden had het begrip interne controle grote betekenis. Met het verschijnen van de bovengenoemde rapporten kwam de nadruk meer op internal control (hier vertaald als interne beheersing) te liggen.

In dit artikel staat het COSO-rapport centraal, omdat dit rapport een breed en algemeen referentiekader geeft voor de beoordeling van het stelsel van beheersingsmaatregelen in een organisatie. Dat dit referentiekader breed gedragen wordt, blijkt wel uit de vele publicaties die over dit onderwerp zijn verschenen (bijvoorbeeld: Den Boer \& Van Zutphen (1995), Hartman (1994) en Van Zutphen (1993)).

In de optiek van COSO is interne beheersing een proces. Dat wil zeggen, het is een middel om een doel te realiseren, maar geen doel op zich. Interne beheersing richt zich daarom niet op het formuleren van ondernemingsdoelstellingen, maar vormt een instrument om te waarborgen dat deze doelstellingen worden gerealiseerd. Het meten van de effectiviteit van de control gebeurt in de Canadese rapporten aan de hand van een aantal beheersingscriteria. Daarbij wordt de effectiviteit steeds beoordeeld in relatie tot de ondernemingsdoelstellingen. Volgens deze rapporten is interne beheersing effectief als het resterende risico met betrekking tot het niet bereiken van de doelstellingen aanvaardbaar is. Internal control bestaat volgens COSO (1994) uit vijf componenten, die zijn geïntegreerd in het managementproces: de beheersingsomgeving (control environment), de risicobeoordeling (risk assessment), de beheersingsactiviteiten (control activities), de informatie en communicatie (information and communication) en de bewaking van een goede werking van het systeem (monitoring).

De complexiteit van derivaten, de snelheid waarmee door derivaten exposures kunnen worden op- of afgebouwd en de omvang waarmee dit gebeurt, maken de beheersing van het gebruik van derivaten tot een belangrijk thema. In dit artikel zijn twee kaders opgenomen waarin een aantal beheersingsmaatregelen zijn weergegeven. Deze beheersingsmaatregelen zijn gebaseerd op de controlcomponenten die in COSO (1994) centraal staan, maar worden hier specifiek toegespitst op het gebruik van derivaten. De component 'risicobeoordeling' is echter uitgebreid tot 'doelstellingen en risico's'. Dit vanwege het belang van de doelstellingen voor het gebruik van financiële derivaten. De kaders zijn bedoeld als illustratiemateriaal, naar volledigheid is niet gestreefd. Zij vormen samen een geheel van beheersingsmaatregelen.

\section{Empirisch onderzoek}

In de voorgaande paragrafen is aangegeven dat de beheersingsmaatregelen voor derivaten uit een aantal componenten zouden moeten bestaan. 
Maatregelen met betrekking tot de beheersingsomgeving

- Het schriftelijk vastleggen van de doelstellingen waarvoor derivaten mogen worden gebruikt en eventueel van de (soorten) derivaten die voor deze doelstellingen mogen worden gebruikt.

- Het eenduidig vastleggen en bekendmaken van verantwoordelijkheden en bevoegdheden ten aanzien van het gebruik van derivaten. Het stelsel van verantwoordelijkheden en bevoegdheden moet consistent zijn en passen binnen de organisatiestructuur.

- Het uitdragen van het beleid voor het gebruik van derivaten door de leiding van de organisatie.

- Het zorgdragen voor voldoende kennis en ervaring van derivaten op alle niveaus in de organisatie.

\section{Maatregelen met betrekking tot doelstellingen en risico's}

- Het duidelijk en ondubbelzinnig vaststellen van de doelstellingen waarvoor derivaten mogen worden gebruikt.

- Het implementeren van hulpmiddelen en mechanismen om de relevante interne en externe risico's te signaleren.

- Het analyseren van de gevoeligheid van vermogen en resultaat voor wijzigingen in rente- of valutaposities, bijvoorbeeld met behulp van scenario analyses of modellen.

- Het in kaart brengen van de risico's die samenhangen met de derivaten die worden gebruikt, alsmede van de risico's die samenhangen met de strategieën en de doelstellingen waarvoor de derivaten worden gebruikt.

- Het in kaart brengen van de risico's die moeten worden afgedekt en de derivaten die hiervoor kunnen worden gebruikt.

\section{Kader 2: Illustratie van een aantal beheersingsmaatregelen per controlcomponent}

Maatregelen met betrekking tot de beheersingsactiviteiten

- Het implementeren van maatregelen gericht op het waarborgen van de juistheid, volledigheid en tijdigheid van de (vastleggingen) van de afgesloten derivatentransacties. In dit verband kan bijvoorbeeld worden gedacht aan functiescheidingen, procedures en richtlijnen, maatregelen in het geautomatiseerde systeem en een stelsel van limieten.

- Het implementeren van maatregelen gericht op het naleven van interne procedures, richtlijnen en het interne beleid voor het gebruik van derivaten, alsmede op het waarborgen dat de doelstellingen van het gebruik van derivaten worden gerealiseerd.

- Het implementeren van maatregelen gericht op de betrouwbaarheid van de interne en externe informatie ten aanzien van het gebruik van derivaten.

\section{Maatregelen met betrekking tot informatie en communicatie}

- Het systematisch verzamelen van gegevens over de interne (zoals bijvoorbeeld wijzigingen in de liquiditeit, de solvabiliteit de vermogenskosten of het investeringsbeleid) en externe omgeving, de voor de organisatie relevante risico's en de relevante ontwikkelingen op financiële markten.

- Het zorgdragen voor tijdige, betrouwbare informatie over het gebruik van derivaten. De structuur van de (interne) informatie moet aansluiten bij de wensen en behoeften van de gebruikers op elk niveau in de organisatie. De beleidsgerichte. uitvoeringsgerichte en verantwoordingsgerichte informatie moet een consistent geheel vormen en aansluiten op de doelstellingen van het gebruik van derivaten.

Maatregelen met betrekking tot de bewaking van de goede werking van de internal control

- Het periodiek beoordelen van de (impliciete) veronderstellingen in het meet- en waarderingssysteem, het beleid en de risicobeoordeling.

- Het periodiek analyseren van de effectiviteit van de gebruikte derivaten in relatie tot de doelstellingen van de organisatie en de daarmee samenhangende verwachtingen. 
Medio 1996 is in het kader van een promotieonderzoek naar de control en audit van financiële derivaten een vragenlijst verstuurd waaraan 38 organisaties hebben meegewerkt. De organisaties die de vragenlijst hebben ingevuld, zijn voornamelijk beursgenoteerde ondernemingen. Twee van de 38 organisaties kunnen tot de categorie 'financiële instellingen' worden gerekend. Drie organisaties behoren tot de categorie andere 'institutionele beleggers'. ${ }^{2}$ Met een aantal organisaties is naar aanleiding van de vragenlijst een nader gesprek gevoerd. De vragenlijst is toegespitst op de beheersingsmaatregelen die bij de vijf controlcomponenten kunnen worden getroffen, zoals vermeld in de kaders 1 en 2 . In tabel 1 wordt een indicatie gegeven van het aantal derivatentransacties dat

Tabel 1: Gemiddeld aantal derivatentransacties per jaar

\begin{tabular}{|l|l|}
\hline $\begin{array}{l}\text { Gemiddeld aantal derivaten- } \\
\text { transacties per jaar: }\end{array}$ & $\begin{array}{l}\text { Aantal } \\
\text { organisaties: }\end{array}$ \\
\hline $0-49$ & 17 \\
$50-99$ & 3 \\
$100-500$ & 7 \\
$>500$ & 7 \\
onbekend & 4 \\
\hline Totaal & 38 \\
\hline
\end{tabular}

door deze organisaties wordt verricht.

Bij het beoordelen van de uitkomsten van de vragenlijst en het interpreteren van de gegevens die uit de gesprekken naar voren zijn gekomen, is aandacht besteed aan:

- de consistentie van de beheersingsmaatregelen;

- de relatie tussen de doelstellingen die met het gebruik van derivaten worden nagestreefd en de geïmplementeerde beheersingsmaatregelen;

- de wijze waarop de maatregelen worden uitgevoerd (systematisch of op ad hoc basis);

- de vraag of de toetsing van de goede werking en de effectiviteit van de maatregelen onderdeel uitmaakt van het beheersingssysteem.

\section{Beheersingsomgeving}

Uit de beantwoording van de vragenlijst blijkt dat het grootste deel van de organisaties (79\%) een schriftelijk beleid met betrekking tot derivaten heeft. Lang niet al deze organisaties (45\%) hebben echter alle elementen (doelstellingen, soorten derivaten die zijn toegestaan, tot welk bedrag en door wie transacties ter zake van derivaten mogen worden aangegaan) hiervan vastgelegd. Het vastleggen van richtlijnen voor het gebruik van derivaten (bijvoorbeeld in de vorm van een handboek) is voor veel organisaties een punt van aandacht.

Het grootste deel $(82 \%)$ van de organisaties geeft aan over een personeelsbeleid te beschikken dat voldoende waarborgen biedt dat het personeel dat wordt aangenomen over voldoende kennis en ervaring beschikt om de werkzaamheden samenhangend met het gebruik van derivaten te kunnen uitvoeren. De kennis van derivaten blijkt echter veelal niet evenwichtig in de organisaties te zijn verdeeld; men geeft aan dat de raad van commissarissen veelal over onvoldoende kennis beschikt. De aandacht voor en de kennis van en over derivaten zal op alle niveaus in de organisatie aanwezig moeten zijn; op dit punt zijn nog verbeteringen mogelijk. 'The tone at the top' bepaalt in belangrijke mate het succes van een beheersingssysteem in een organisatie. Hierdoor is het van groot belang dat de leiding van een organisatie adequaat reageert op gebreken in de opzet en werking van het beheersingssysteem.

\section{Doelstellingen en risico's}

Alle organisaties die aan het onderzoek hebben meegewerkt, kunnen aangeven voor welke doelstellingen derivaten worden gebruikt. Bij 31 organisaties worden derivaten gebruikt voor de beheersing van valutarisico's (het gaat daarbij om het beheersen van de transactie-exposure ${ }^{3}$ ) en bij 28 organisaties voor de beheersing van renterisico's. Derivaten worden slechts in elf gevallen gebruikt voor het optimaliseren van financieringsbeslissingen en in vijf gevallen voor het optimaliseren van beleggingsbeslissingen. Er zijn drie organisaties die derivaten ook gebruiken als zelfstandig middel tot winst.

De meeste organisaties (79\%) beschikken over een mechanisme om relevante interne en externe risico's te signaleren. Deze mechanismen leiden echter niet altijd tot een systematische analyse van de omgevingsfactoren.

Hoewel de doelstellingen door de meeste organisaties worden genoemd, blijkt dat het niet 
altijd duidelijk is welke strategieën wel en welke strategieën niet tot deze doelstellingen behoren. Bijvoorbeeld: behoort het afdekken van een toekomstige positie nu wel of niet tot de doelstelling 'beheersen van risico's'? Organisaties zullen dus meer aandacht moeten besteden aan het helder en eenduidig formuleren van doelstellingen en definities. De risico's waaraan de organisatie is blootgesteld worden bovendien maar in een zeer beperkt aantal gevallen met behulp van modellen en/of scenario analyses in kaart gebracht. Meerdere organisaties kunnen met behulp van eenvoudige middelen (zoals bijvoorbeeld een spreadsheetprogramma) een indicatie van de gevoeligheid van vermogen en resultaat voor wijzigingen in renteen valutaposities geven.

De risico's die met derivaten samenhangen worden door weinig organisaties geanalyseerd. Meting van deze risico's en van de effecten van veranderende marktsituaties vindt alleen door financiële instellingen en andere institutionele beleggers plaats. Er zijn bovendien weinig organisaties die het limietenstelsel baseren op de uitkomsten van de gevoeligheidsanalyses/modellen en het daaruit berekende potentiële verlies, dan wel op de omvang van het weerstandsvermogen.

Organisaties die structureel derivaten gebruiken. zullen meer aandacht moeten besteden aan het meten en beheersen van risico's. Daarnaast blijft het zaak om te analyseren of de doelstellingen waarvoor derivaten worden gebruikt, niet (onbewust) leiden tot risico's die de organisatie niet kan dragen.

\section{Beheersingsactiviteiten}

Bij financiële derivaten is het van belang dat de afgesloten transacties juist, volledig en tijdig worden geregistreerd, waarbij ook voorwaardelijke rechten en verplichtingen moeten worden vastgelegd. Deze maatregelen kunnen preventief (bijvoorbeeld limietenstelsel, functiescheidingen) of repressief (bijvoorbeeld het controleren van geregistreerde gegevens met externe documenten) van aard zijn.

In het algemeen kan op basis van het onderzoek worden geconstateerd, dat aan de opzet van de administratieve organisatie en de maatregelen van interne controle vrij veel aandacht wordt geschonken. Ook blijkt dat de meeste organisaties $(89 \%)$ beschikken over procedures voor het gebruik van derivaten.

Het aantal derivatentransacties dat wordt afgesloten, bepaalt echter in belangrijke mate de omvang en effectiviteit van deze maatregelen. Een onafhankelijke risk manager werd bijvoorbeeld alleen bij een financiële instelling aangetroffen. Een groot gedeelte van de organisaties beschikt over een limietenstelsel. Bij een aantal organisaties gaat het echter niet om een formeel limietenstelsel, maar om de onderliggende positie. Voor het afdekken van de positie bestaan dan autorisatieprocedures. Er is maar een enkele organisatie die afzonderlijke procedures heeft voor het afsluiten van transacties in OTC-derivaten of transacties boven een bepaald bedrag.

Hoewel formeel al veel is geregeld, kan worden geconstateerd dat er materieel nog veel te verbeteren valt. De afdeling die de transacties afsluit (front-office) en de afdeling die hierop controle uitoefent (soms is dit de back-office, in andere gevallen bijvoorbeeld de afdeling interne controle) hebben lang niet altijd een gelijkwaardige positie. Vaak ontbreekt het de controlerende afdeling aan kennis om als countervailing power op te treden voor de front-office. Ook functioneel heeft het hoofd van de front-office veelal een hogere positie dan het hoofd van de back-office.

De uitvoering van een aantal controles - zoals bijvoorbeeld het toetsen of transacties passen binnen het beleidskader, het controleren van geregistreerde gegevens met bevestigingen van derden, het toetsen of bevoegdheden niet zijn overschreden en of autorisatieprocedures zijn nageleefd - geschiedt in $84 \%$ van de gevallen door de back-office, al dan niet samen met een andere afdeling (veelal is dat de interne accountantsdienst).

Hoewel alle organisaties intern een aantal controlerende werkzaamheden uitvoeren, is het opvallend dat relatief weinig organisaties de componenten van het (on)gerealiseerde resultaat van de transacties en de hiermee samenhangende verplichtingen analyseren (dit gebeurt door 18 organisaties). Uit het onderzoek blijkt dat het beoordelen van de effectiviteit van de afgesloten transacties in relatie tot de doelstellingen lang niet 
altijd plaatsvindt. Dit geldt ook voor de werking van de beheersingsmaatregelen en voor de beoordeling van de vooronderstellingen die aan de gebruikte modellen en analyses ten grondslag liggen.

Een groot gedeelte van de organisaties geeft ten slotte aan dat de organisatorische maatregelen adequaat zijn verwerkt in het geautomatiseerde systeem. In een aantal gevallen is er een georganiseerd overleg waarin het treasurybeleid wordt besproken.

\section{Informatie en communicatie}

Een organisatie die derivaten wil gebruiken, moet over tijdige en betrouwbare informatie beschikken om beslissingen te nemen en verantwoording af te leggen. In dit verband kan een onderscheid worden gemaakt tussen beleidsgerichte, uitvoeringsgerichte en verantwoordingsgerichte informatie. Beleidsgerichte informatie vormt als het ware de norm waarmee de resultaten van het gebruik van derivaten kunnen worden beoordeeld. Uitvoeringsgerichte informatie heeft betrekking op de informatie die nodig is om operationele beslissingen te nemen. Verantwoordingsgerichte informatie heeft betrekking op het afleggen van verantwoording over deze activiteiten aan interne of externe belanghebbenden.

De beleidsgerichte en uitvoeringsgerichte informatie is voor een belangrijk deel afkomstig uit modellen en scenario analyses. Gedacht kan worden aan kasstroomprognoses, analyses van renterisico's, enz. Het blijkt echter dat maar een beperkt aantal organisaties op een systematische en diepgaande wijze van modellen en analyses gebruikmaakt en dus in staat is om hierover te rapporteren.

Er zijn zes organisaties die gebruikmaken van modellen om:

- de gevoeligheid van vermogen en resultaat voor wijzigingen in rente- en valutaposities te bepalen;

- het effect van veranderende marktsituaties op de waarde van de derivatenportefeuille te bepalen;

- het potentiële verlies dat samenhangt met de derivatenportefeuille vast te stellen.

Ten aanzien van verantwoordingsgerichte informatie kan worden opgemerkt dat het bestu- rend orgaan lang niet altijd informatie ontvangt over potentiële risico's en verliezen, alsmede over beheersingsproblemen.

\section{Bewaking van de goede werking van de internal control}

De vijf componenten van internal control vormen één samenhangend en dynamisch geheel. Om de kwaliteit van de internal control te waarborgen, zijn dan ook monitoringactiviteiten en afzonderlijke audits nodig. Door middel van monitoringactiviteiten kan worden gesignaleerd of wijzigingen in de controlcomponenten en/of de omgeving hebben plaatsgevonden. Door middel van audits kan worden vastgesteld dat de beheersingsmaatregelen conform opzet hebben gewerkt. Een effectieve monitoring vereist ook geschikte follow-up mechanismen. Gesignaleerde gebreken in het beheersingssysteem moeten leiden tot aanpassing van het systeem.

Het blijkt dat de effectiviteit van de derivatentransacties niet of in zeer beperkte mate wordt beoordeeld. De interne auditors blijken bovendien lang niet altijd te beschikken over voldoende deskundigheid en voeren vaak op ad hoc basis onderzoek uit. De algemene conclusie is dan ook dat hoewel op onderdelen het een en ander geregeld is, met name de structuur en samenhang van de controlcomponenten kan worden verbeterd. In dit kader is ook de auditfunctie van belang. De goede werking van de internal control wordt immers mede bewaakt door het uitvoeren van audits.

\section{Samenvatting en conclusies}

Uit literatuuronderzoek blijkt dat beheersingsmaatregelen een dynamisch en consistent geheel moeten vormen dat samenhangt met doelstellingen die worden nagestreefd. Toegespitst op derivaten zou dit moeten betekenen dat de beheersingsmaatregelen waarborgen dat de doelstellingen van derivaten worden gerealiseerd, terwijl de risico's die ermee samenhangen tot een voor de organisatie aanvaardbaar niveau worden teruggebracht. Het risicomanagement neemt daarbij een centrale plaats in. In de praktijk ontbreekt het met name aan consistentie tussen de controlcomponenten, aan integratie van het risicomanagement van derivaten in de overall risicobeoordeling van de 
organisatie en aan een periodieke beoordeling van de mate waarin de geformuleerde doelstellingen worden gerealiseerd.

Op basis van onderzoek is een beeld verkregen van de in Nederland gebruikte beheersingsmatregelen voor derivaten. De voorlopige resultaten van dit onderzoek geven aan dat op de volgende punten verbeteringen wenselijk zijn:

1 De effectiviteit van de gebruikte derivaten in relatie tot de doelstellingen die ermee worden nagestreefd, zou periodiek moeten worden beoordeeld.

2 Organisaties moeten zorgdragen voor een breed draagvlak voor het beheersingssysteem. Hiervoor is het noodzakelijk dat op alle niveaus toereikende informatie beschikbaar is om beslissingen te nemen, beleid te ontwikkelen en verantwoording af te leggen.

3 De controlerende afdeling moet over voldoende kennis en ervaring beschikken om tegenwicht te kunnen bieden aan de front-office. Om dit te bewerkstelligen zal er in deze organisatie voldoende kennis en ervaring aanwezig moeten zijn. Diarnaast zal het hoofd van deze afdeling een gelijkwaardige positie als het hoofd van de tront-office moeten hebben.

4 Organisaties zijn in het algemeen goed in staat om aan te geven voor welke doelstellingen derivaten worden gebruikt. Ondanks dat is er een aantal onduidelijkheden in terminologie. gebruik van derivaten en beheersing van hel gebruik van derivaten. Onduidelijkheden ontstaan ook als de organisatie derivaten niet alleen gebruikt als middel om risico's te beheersen, maar ook het 'speculatief gebruik' niet wil uitsluiten. Om deze reden is het van belang dat er in de organisatie eenduidigheid bestaat van definities. doelstellingen en methoden.

5 Er is meer aandacht nodig voor het analyseren en meten van risico's samenhangend met het gebruik van derivaten, alsmede voor het analyseren van de (potentiële) gevolgen van deze risico's voor het vermogen en resultaat van de organisatie. Dit wordt des te belangrijker voor een organisatie als het aantal deriva- tentransacties dat wordt afgesloten toeneemt. de stabiliteit en voorspelbaarheid van kasstromen afneemt en er geen één op één relatie is tussen afgesloten transactie en onderliggende positie.

6 Om blijvend de goede werking van het beheersingssysteem te waarborgen. is het van belang dat er in de organisatie voldoende mechanismen zijn die tijdig veranderingen kunnen signaleren. In dit verband moet ook de audit van de beheersingsmaatregelen adequaat worden geregeld. Het gaat hier met name om de volgende punten:

- de rol van de verschillende auditors (interne en externe accountant. back-office, interne controle-afdeling, enz.) zal duidelijk moeten worden vastgelegd:

- de aard en omvang van het onderzoek dat wordt uitgevoerd moeten bekend zijn in de organisatie en niet beperkt blijven tot de linanciële verantwoording;

- de audits moeten minder op ad hoc basis plaatsvinden: waar mogelijk zal moeten worden gestreefd naar een systematische audit van de vijf controlcomponenten.

\section{I T E R A T U U R}

Alexander, C., (1995), A primer on financial derivatives, Canadian Economic Observer, November, 3.1-3.14.

Basle Committee on Banking Supervision, (1994), Risk management guidelines for derivatives, Basle.

Beek, R.J. van en J.H.G. Kinds, (1996), Interne beheersing en accountant, Literatuurstudie en synthese, studierapport uitgebracht door het Koninklijk NIVRA.

Boer, H. den \& L.C. van Zutphen, (1995), Business control en auditing, recente ontwikkelingen in internationaal verband, Academic Service

Boot, A.W.A. en J.E. Ligterink, (1995), Derivaten: zinvolle toepassingen en het grote onbegrip, Economisch Statistische Berichten, 22 maart 1995.

Boot, A.W.A. en J.E. Ligterink, (1995), Naar een verantwoord gebruik van derivaten, Economisch Statische Berichten, 5 april 1995

Boni, R.T., (1994), The Risks of Derivatives, Swiss Bank Corporation, Economic and Financial Prospects, Special issue on derivatives.

Canadian Institute of Chartered Accountants, (1994), Guidance on criteria of control, exposure draft.

Canadian Institute of Chartered Accountants, (1995), Guidan- 
ce on control.

Committee of Sponsoring Organisations of the Treadway Commission, (1994), Internal Control - Integrated Framework, AICPA.

Committee of Sponsoring Organisations of the Treadway Commission, (1996), Internal Control Issues in derivatives usage; an information tool for considering the COSO Internal Control - Integrated Framework in derivatives applications, AICPA.

Ernst \& Young, (1994), Derivatives, managing the risks.

Hartman, W., (1994), 'Internal Control' als beheersingsproces, De Accountant, juli/augustus 1994.

Ministerie van Financiën, (1995), Circulaire inzake het gebruik van derivaten in het treasurybeleid van openbare lichamen, Den Haag, 15 februari 1995.

Nationale Woningraad, (1994), Handreiking financierings- en beleggingsstatuut, Informatiebulletin nr. 1994-80.

Swaan, T. de, (1996), Risicomanagement: de invalshoek van de toezichthouder, pre-advies voor de NIBE-jaardag 1996. Zutphen, (1993), L.C. van, Het COSO-studierapport, Inleiding en commentaar, Maandblad voor Accountancy en Bedriffseconomie, mei 1993.

\section{N O T E N}

1 Zie Risk management guidelines for derivatives, blz. 3 .

2 Tot de categorie 'andere institutionele beleggers' behoren in dit onderzoek twee pensioenfondsen en één vermogensbeheerder.

3 Het gaat hier om het afdekken van het risico dat het resultaat op een transactie afwijkt van het verwachte resultaat door een verandering van de wisselkoers gedurende de periode tussen begin en einde van de transactie. 